Curr Opin Psychiatry. Author manuscript; available in PMC 2013 July 17.

Published in final edited form as:

Curr Opin Psychiatry. 2008 November ; 21(6): 593-597. doi:10.1097/YCO.0b013e32830aba12.

\title{
History of psychiatry
}

\section{Edward Shorter}

Faculty of Medicine, University of Toronto, Toronto, Ontario, Canada

\begin{abstract}
Purpose of review-The present review examines recent contributions to the evolving field of historical writing in psychiatry.
\end{abstract}

Recent findings-Interest in the history of psychiatry continues to grow, with an increasing emphasis on topics of current interest such as the history of psychopharmacology, electroconvulsive therapy, and the interplay between psychiatry and society. The scope of historical writing in psychiatry as of 2007 is as broad and varied as the discipline itself.

Summary-More than in other medical specialties such as cardiology or nephrology, treatment and diagnosis in psychiatry are affected by trends in the surrounding culture and society. Studying the history of the discipline provides insights into possible alternatives to the current crop of patent-protected remedies and trend-driven diagnoses.

\section{Keywords}

electroconvulsive therapy; psychiatric epidemiology; psychiatry and society; psychopharmacology

\section{Introduction}

Interest in the history of psychiatry continues to grow, shifting from curiosity about the history of psychoanalysis and Freud's Vienna to the history of psychopharmacology, electroconvulsive therapy (ECT) and neuroscience, subjects more in the forefront today. Yet the scope of historical writing in psychiatry is as broad as the discipline itself, and the history of psychiatry in 2007 has tumbled into many variegated nooks and crannies.

\section{History of psychopharmacology}

Among senior figures in psychopharmacology, Thomas A. Ban, emeritus professor of psychiatry at Vanderbilt University, has applied himself most consistently to the discipline's history over the years. In 2006, Ban [1*0] described the relationship among diagnosis, pharmaceutical industry, and clinical trials, postulating that "development of a pharmacologically valid psychiatric nosology with a "nosological matrix" would provide the pharmaceutical industry with the necessary feedback to develop clinically selective drugs in mental illness and to break the impasse of progress in "translational research" in psychiatry'

Correspondence to Edward Shorter, Hannah Chair in the History of Medicine/Professor of Psychiatry, Faculty of Medicine, University of Toronto, 88 College Street, Room 207, Toronto, Ontario, Canada Tel: +1 416978 2124; fax: +1 416971 2160; 
(p. 429). Ban also wrote a history of the Collegium Internationale Neuro-

Psychopharmacologicum $\left[2^{\circ}\right]$.

Klein $\left[3^{\circ}\right]$, another senior psychopharmacologist, has described his early experiences with antipsychotics, ending with thoughts about regulatory changes needed today. Emil Kraepelin, the founder of modern psychiatric nosology, now excites great interest, and a team of German and English scholars, using published sources, has chronicled his early psychopharmacological research [4].

Finally, Turner [5], a consultant psychiatrist in London with a long track record of publication in the history of psychiatry, looks at the discovery of chlorpromazine (Thorazine, Largactil) in 1952 as 'a kind of psychic penicillin' that opened the therapeutics of psychosis.

\section{Psychiatry and bioethics}

The accent here is usually on the Nazi years. Notable is the work of a team of scholars at the Max Planck Institute for Psychiatric Research in Munich on the relationship between intellectual giftedness and psychiatric illness $\left[6^{\circ}\right]$. A Spanish-English team, López-Munoz et al. [7], gives us a quick overview of Nazi medicine in the Holocaust as well, drawing appropriate present-day parallels.

\section{Autobiography/biography/obituaries}

A subject of perennial interest in psychiatry is that the lives of important psychiatrists have the capacity to inspire - sometimes to repel - and to capture the human drama of the discipline's way forward. Among the notable contributions is McGlashan and Carpenter's [8] commemoration of the late Wayne Fenton's contribution to schizophrenia studies.

Jerome Frank at Johns Hopkins University is remembered for, among other things, introducing the concept of demoralization, a useful term deserving of revival. De Figueiredo $\left[9^{\circ}\right]$ at Yale University, a former student of Frank, reminds us of this accomplishment.

For linguistic reasons, the life of Sergey Korsakov, who described the alcoholic polyneuritis that was later named after him, has been largely inaccessible to scholarly inquiry. A step towards filling this gap is a brief biography by two Russian clinicians, Ovsyannikov and Ovsyannikov [10] placing Korsakov in context.

Kerr and Kay $\left[11^{\circ}\right]$ have given us a beautifully written appreciation of the life and achievements of the late Sir Martin Roth, one of the leading figures in twentieth century British - and world - psychiatry.

Hilton $\left[12^{\circ}\right]$ has written an exhaustively researched account of the life of the Maudsley's Felix Post, one of the founders of geriatric psychiatry, as well as commemorating an important figure; the memorial gives an insight into British psychiatry in the postwar era.

An absolutely charming memoir of psychiatry's institutional past is the account of the Worcester State Hospital in Massachusetts in the 1940s by Callaway [13*], where he was a resident. 
The great Spanish psychiatrist Juan López Ibor coined the term 'vital anxiety', borrowing from Kurt Schneider's 'vital depression'. López Ibor introduced the German tradition into Spanish psychiatry, and Lidesmo-Jimeno [14] gives an overview of his life.

\section{Famous patients}

Along with studies of famous psychiatrists are those of famous patients, once called 'pathographies' when written by physicians. In this year's collection of reviews, there are no formal pathographies, yet of interest is a Swiss group's extensively documented reanalysis of the symptoms of French novelist Gustav Flaubert, concluding that he might have had a tic disorder $\left[15^{\circ}\right]$.

Drawing upon the resources of St Elizabeths Hospital in Washington, District of Columbia, formerly the mental hospital of the Public Health Service, researcher Kleiman [16 $\left.{ }^{\circ}\right]$ studies the records of Stanley McCormick, a member of the International Harvester dynasty, whose clinician was William Alanson White.

Shawn [17'], son of New Yorker magazine's legendary editor William Shawn, has written an account of his own phobic illness that journalist Malcolm [18 ${ }^{\circ}$ ], a frequent New Yorker contributor, engagingly noticed in the New York Review of Books. Literary-minded readers will appreciate both the memoir and the review.

Lerner [19*0], professor of medicine at Columbia University and veteran historian of medicine, has analyzed various accounts of Franklin Roosevelt's terminal illness with the aid of archival sources, including the question of the president's mental competency at the time of the Yalta agreements (fully competent is the answer).

\section{Psychoanalysis}

The decline of interest in Freud's doctrines among clinicians has been matched by that among historians. Yet, so vast was the previous curiosity about the history of psychoanalysis that in relative terms, a considerable volume of literature persists.

The tragic emigration abroad of German-Jewish psychiatrists in the Nazi years has been often chronicled. The story of Hans Erich Haas, the first psychoanalyst in the German city of Cologne, and his emigration to Birmingham (where he also was the first psychoanalyst) is now recounted in detail by Schultz-Venrath [20].

Firmly archive based is the study of the stay of Freud's father in Leipzig in 1859 by Schröter and Tögel [21 $]$, which originally appeared in German.

Given the ongoing closure of collections in the Freud archives in the Library of Congress and elsewhere, archive-based findings in the Freud world are few and far between, the literature consisting mainly of endless reinterpretations of well known texts and collection of letters. Yet, not all are without interest, for example, the study of Anna Freud's role in the Hampstead War Nurseries by Midgley [22 ${ }^{\circ}$. 
The 'Schreber case' continues to fascinate, as Martin [23], at the School of Education of the University of Birmingham, adds Tourette's syndrome to the growing list of possible illnesses that Daniel Paul Schreber, whose published memoirs crystallized Freud's thinking about paranoia, might have had (neurosyphilis seems the most likely candidate to the present reviewer). Freud adepts who miss nothing will not want to miss the review of how Freud came to some of his ideas, including free association, by Brenner [24], based on Freud's works and several references from the second generation of analysts.

\section{Psychiatry and neuroscience}

Psychiatry and neuroscience is an important area of psychiatric history that was poorly reviewed in 2007, and only a single article, albeit an important one, need be cited, as interest in the history of neuroendocrinology and neuroimmunology starts to develop. Irwin and Miller [25] at the University of California Los Angeles Cousins Center for Psychoneuroimmunology give us an overview of 20 years of progress in 'depressive disorders and immunity', concluding that a 'cytokine model of depression' offers 'drug targets for further development' (p. 374).

\section{Psychiatry and society}

More than disciplines such as cardiology or nephrology, psychiatric treatment and diagnosis are affected by the surrounding culture and society. Witness the inability of psychiatry to protect itself from various fads, such as the current vogue for 'pediatric bipolar disorder', that sweep back and forth. This is not to say that other medical specialties are immune to faddish thinking, but merely that the problem is worse in psychiatry because, in the absence of a good model of pathophysiology, psychiatry is unable to prove faddish new ideas wrong. Apropos of the above, Bendersky [26 $]$, professor of German and intellectual history at Virginia Commonwealth University, reviews the impact of Gustav Le Bon's thinking about 'panic' on US military psychology during the Second World War. Le Bon was the father of social psychology, and his 1895 book, The Crowd, had a major impact on understanding mass behavior.

A triumph of linking clinical psychiatry to surrounding social trends is The Loss of Sadness by Horwitz and Wakefield [27०0], a highly readable and well informed indictment of the Diagnostic and Statistical Manual of Mental Disorders and of psychiatry's ties to the pharmaceutical industry. The book has attracted much media attention and provides sobering reading for clinicians.

2007 has been a year of assaults on trendy diagnoses, including a scathing review of 'social anxiety disorder' by Lane [28*0], a medical historian at Northwestern University.

Transcultural psychiatry belongs par excellence in the rubric 'psychiatry and society' because its premise is that the surrounding culture changes the presentation of psychiatric illness as well as attitudes towards it. Littlewood et al. [29 $]$ examine the cross-national stigmatization of serious psychiatric illness using an 'ethnographically grounded questionnaire' on seven cultures from England to India to the Caribbean and West Africa. 
Interest among medical historians in the history of shell shock and combat fatigue in wartime has been considerable. US psychiatrist Harry Stack Sullivan developed a questionnaire to screen out the 'unfit' in World War II, and Wake [30*0], an assistant professor in science history at Michigan State University, examines this story in the context of the history of military psychiatry. Despite being homosexual himself, by 'unfit' Sullivan seems to have meant primarily gay men.

France has always been distinctive in psychiatric history, having, for example, the world's highest rate of consumption of benzodiazepines. Psychiatrist Verdoux [31] in Bordeaux examines the excessive emphasis on institutional care in France and the corresponding under-development of community services (often called 'sectorization'). Interestingly, France has one of the largest numbers of psychiatrists in the world (many of them still given to psychoanalysis).

\section{Psychiatric epidemiology in historical perspective}

The enormous deployment of resources that epidemiology requires means that, in historical epidemiology as well, only determined groups with considerable resources are able to make a mark. Of these, the historical psychiatry group led by David Healy in Bangor, North Wales, has made several important contributions over the years. Of note in 2007 was their comparison of patients with manic-melancholic syndromes admitted to the North Wales asylum from 1875 to 1924 and to the North West Wales mental health services between 1995 and 2005. The authors found a significant decline in the incidence of postpartum psychoses, although the occurrence of melancholia as a whole remained stable. The authors further suggest that the concept of 'manic-melancholic disorder' by Rafaelsen [32] in 1974 might well replace 'major depression' $\left[33^{\circ}\right]$.

\section{Electroconvulsive therapy}

Given the revival of interest of ECT in psychiatry, its history is also receiving renewed attention. Passione [34*0], a medical historian at the University of Bologna, has written a comprehensive biography of Ugo Cerletti, the originator of ECT, reviewing his complex relationship with Mussolini's regime as well as the scientific story. As for utilization, one Danish study finds ECT stable over the last 15 years; its indications, however, shift from bipolar and schizoaffective disorders to unipolar depression [35]. Yet, the use of ECT has always been high in Denmark, so a failure to rise even further might not be entirely typical. Indeed, Shorter and Healy [36*0], in the first comprehensive history of ECT, do find that in the US, the use of ECT has recently been on the rise, a result of lessening the often horrendous stigmatization to which the procedure was subject from the 1960s to the 1980s. (Given this reviewer's coauthorship, it is embarrassing to flag the book with double stars, yet it does offer a comprehensive overview - the first ever written - of the history of shock therapy from the 1930s to our own times.) 


\section{Conclusion}

The history of psychiatry should be a fundamental part of resident training. More than a mere grab bag of historical curiosities for the diversion of established clinicians, psychiatric history offers insights into treatments and diagnoses that once flourished and now, perhaps unfairly, have been crowded from the stage to the advantage of patent-protected remedies and trendy diagnoses. There is much of benefit in psychiatry's past - safe and effective therapeutic agents and diagnoses that cut nature at the joints perhaps even better than the current crop. Psychiatrists in training as well as senior practitioners should become aware of the historical existence of alternative therapies and diagnoses.

\section{References and recommended reading}

Papers of particular interest, published within the annual period of review, have been highlighted as:

- of special interest

•• of outstanding interest

Additional references related to this topic can also be found in the Current World Literature section in this issue (pp. 656-657).

1•. Ban TA. Academic psychiatry and the pharmaceutical industry. Prog Neuropsychopharmacol Biol Psychiatry. 2006; 30:429-441. Ban has written many thoughtful commentaries over the years about these interrelationships, but often in obscure journals, and his work figures centrally in any effort to return diagnosis and treatment in psychiatry to a scientific basis. [PubMed: 16442686]

2. Ban TA. A history of the Collegium Internationale Neuro-Psychopharmacologicum (1957-2004). Prog Neuropsychopharmacol Biol Psychiatry. 2006; 30:599-616. An insider's account of the origins and development of the first association devoted to the specialty. [PubMed: 16564121]

3. Klein DF. Commentary by a clinical scientist in psychopharmacological research. J Child Adolesc Psychopharmacol. 2007; 17:284-287. This review discusses historical developments and current problems in the regulation of psychopharmaceuticals. [PubMed: 17630859]

4. Müller U, Fletcher PC, Steinberg H. The origin of psychopharmacology: Emil Kraepelin's experiments in Leipzig. Dorpat and Heidelberg (1882-1892). Psychopharmacology. 2006; 184:131138. [PubMed: 16378216]

5. Turner T. Unlocking psychosis. BMJ. 2007; 334:s7. [PubMed: 17204765]

6••. Wiedemann U, Burgmair W, Weber MM. The highly gifted persons study by Adele Juda 19271955: pinnacle and end of psychiatric genius research in Germany. Sudhoffs Arch. 2007; 91:2037. This review traces the background of the large collection of documentary records on the relationship between high intelligence and mental illness assembled by Adele Juda during the Hitler era and published in 1953. [PubMed: 17564157]

7. López-Munoz F, Alamo C, Dudley M, et al. Psychiatry and political-institutional abuse from the historical perspective: the ethical lessons of the Nuremberg Trial on their $60^{\text {th }}$ anniversary. Prog Neuropsychopharmacol Biol Psychiatry. 2007; 31:791-806. [PubMed: 17223241]

8. McGlashan TH, Carpenter WT. Identifying unmet therapeutic domains in schizophrenic patients: the early contributions of Wayne Fenton from Chestnut Lodge. Schizophr Bull. 2007; 33:10861092. [PubMed: 17634414]

9•. De Figueiredo JM. Demoralization and psychotherapy: a tribute to Jerome D. Frank, MD, PhD (1909-2005) Psychother Psychosom. 2007; 76:129-133. This important is important for highlighting Frank's introduction of this important psychotherapeutic concept.

10. Ovsyannikov SA, Ovsyannikov AS. Sergey S. Korsakov and the beginning of Russian psychiatry J Hist Neurosci. 2007; 16:58-64. [PubMed: 17365552] 
11 . Kerr A, Kay D. Sir Martin Roth, FRS. Br J Psychiatry. 2007; 190:375-378. A concise review of Roth's accomplishments; the article includes a photograph of a scowling, forbidding Sir Martin. [PubMed: 17470950]

12•. Hilton C. The life and work of Felix Post (1913-2001): pioneer in the psychiatry of old age. J Med Biog. 2007; 15:31-37. An extensively researched account, the study contains 121 references and is based, among other sources, on interviews.

13••. Callaway E. Asylum: a mid-century madhouse and its lessons about our mentally ill today. Westport: Praeger;. 2007 Fans of psychiatrists' autobiographies will relish Callaway's vivid reminiscences of the Worcester State Hospital during the 1940s.

14. Ledesma-Jimeno AL. Lopez Ibor versus Freud and forerunner of psychiatric nosology. Actas Esp Psiquiatr. 2007; 35:1-7.

15•. Arnold LM, Baumann CR, Siegel AM. Gustav Flaubert's 'nervous disease': an autobiographic and epileptological approach. Epilepsy Behav. 2007; 11:212-217. 'In our opinion, psychopathological considerations suggest primary involvement of the mesial temporal lobe structures with typical findings of ictal and interictal mood behavior.' (p. 212). [PubMed: 17681494]

16••. Kleiman M. Rich, famous, and questionably sane: when a wealthy heir's family sought help from a hospital for the insane. US Natl Arch Rec Adm. 2007; 39(2):38-47. [Accessed 15 May 2008] http://www.archives.gov/publications/prologue/2007/summer/mccormick.html. This riveting use of archival records shows what can be accomplished with the enormous number of patient files from St. Elizabeths, now in the National Archives.

17. Shawn, A. Wish I could be there: notes from a phobic life. New York: Viking; 2007. An engaging autobiographical contribution to 'illness narrative' literature

18•. Malcolm J. 'The not returning part of it': [review of] wish I could be there: notes from a phobic life. NY Rev Books. 2007; 54:4-6. Shawn's reviewer Janet Malcolm has written widely on psychiatry, including studies of the Freud archive and its misadventures under archivist Jeffrey Masson.

19••. Lerner BH. Crafting medical history: revisiting the 'definitive' account of Franklin D. Roosevelt's terminal illness. Bull Hist Med. 2007; 81:386-406. In discussing the primary sources, Lerner reminds us that 'this historiography also demonstrates another key point: all historical scholarship remains embedded in the era in which it was written.' (p. 405). [PubMed: 17844721]

20. Schultz-Venrath U. A forgotten chapter in the prehistory of psychoanalysis in Cologne. The emigration of Hans Erich Haas (1896-1990). Luzifer-Amor. 2007; 20:53-71. [PubMed: 17992842]

21. Schröter M, Tögel C. The Leipzig episode in Freud's life (1859): a new narrative on the basis of recently discovered documents. Psychoanal Q. 2007; 76:193-215. This study, on the basis of primary sources, has now been made available to an English-speaking audience. [PubMed: 17294826]

22. Midgley N. Anna Freud: the Hampstead War Nurseries and the role of the direct observation of children for psychoanalysis. Int J Psychoanal. 2007; 88:939-959. On the basis of no new archival research, yet this review is of interest for detailing Anna Freud's role in the work of this important wartime facility. [PubMed: 17681901]

23. Martin G. Schreber's 'Bellowing Miracle': a new content analysis of Daniel Paul Schreber's memoirs of my nervous illness. J Nerv Ment Dis. 2007; 195:640-646. [PubMed: 17700295]

24. Brenner C. Freud's great voyage of discovery. Psychoanal Q. 2007; 76:9-25. [PubMed: 17294822]

25. Irwin MR, Miller AH. Depressive disorders and immunity: 20 years of progress and discovery. Brain Behav Immun. 2007; 21:374-383. [PubMed: 17360153]

26•. Bendersky JW. 'Panic': the impact of Le Bon's crowd psychology on U.S. military thought. J Hist Behav Sci. 2007; 43:257-283. In addition to providing a comprehensive grasp of the literature, the article draws upon material from the US military archives. [PubMed: 17623871]

27••. Horwitz, AV., Wakefield, JC. The loss of sadness: how psychiatry transformed normal sorrow into depressive disorder. New York: Oxford University Press; 2007. The authors, Horwitz, a sociologist at Rutgers University, and Wakefield, a professor of social work at New York 
University are veteran critics of psychiatry but thoughtful ones and not antipsychiatric in orientation

28••. Lane, C. Shyness: how normal behavior became a sickness. New Haven: Yale University Press; 2007. Partly on the basis of interviews and the archives of the American Psychiatric Association, Lane has written a scorching critique of the medicalizing of normal emotion

29•. Littlewood R, Jadhav S, Ryder AG. A cross-national study of the stigmatization of severe psychiatric illness: historical review, methodological considerations and development of the questionnaire. Transcult Psychiatry. 2007; 44:171-202. The authors consider changes over time as well as cultural differences in attitudes to psychiatric illness. [PubMed: 17576725]

30••. Wake N. The military, psychiatry, and 'unfit' soldiers, 1939-1942. J Hist Med Allied Sci. 2007; 62:461-494. For background on Harry Stack Sullivan, creator of the questionnaire to eliminate the 'unfit', the author studied psychiatric case records from the Sheppard-Pratt Hospital in Baltimore as well as other archival sources. [PubMed: 17309903]

31. Verdoux H. The current state of adult mental healthcare in France. Eur Arch Psychiatry Clin Neurosc. 2007; 257:64-70.

32. Rafaelsen OJ. Manic-depressive psychosis or manic-melancholic mode. Dan Med Bull. 1974; 21:81-87. [PubMed: 4840739]

33. Farquhar F, Le Noury J, Tschinkel S, et al. The incidence and prevalence of manic-melancholic syndromes in North West Wales: 1875-2005. Acta Psychiatr Scand Suppl. 2007; 115:37-43. The authors were puzzled by the virtual disappearance of postpartum psychoses and argued 'for the possibility that within the group of postpartum psychoses there may be a disorder distinct from other affective or nonaffective psychotic disorders'. (p. 43).

34••. Passione, R. Cerletti: the history of electroshock. Reggio Emilia: Aliberti; 2007. Passione's groundbreaking biography of Cerletti and his development of ECT rest extensively on archival materials in addition to an impressive knowledge of the published sources

35. Munk-Olsen T, Laursen TM, Videbech P, et al. Electroconvulsive therapy: predictors and trends in utilization from 1976 to 2000. J ECT. 2006; 22:127-132. [PubMed: 16801829]

$36 \bullet$. Shorter, E., Healy, D. Shock therapy: the history of electroconvulsive treatment in mental illness. New Brunswick: Rutgers University Press; 2007. The first comprehensive history of convulsive treatments, the book is based heavily on archival sources and interviews as well as literature in four languages 